551.578 .1

\title{
Life Time of Water Drops before Breaking and Size Distribution of Fragment Droplets*
}

\author{
by M. Komabayasi, T. Gonda and K. Isono \\ Water Research Laboratory, Nagoya University \\ (Manuscript received 17 July 1964)
}

\begin{abstract}
Life times of water drops before breaking suspended freely in a vertical air stream have been empirically determined as a function of drop diameter. It has been found that breaking probability of a drop increases with increasing drop diameter. Average life times are $273 \mathrm{sec}$ at $5.5 \mathrm{~mm}, 63.4 \mathrm{sec}$ at $6.5 \mathrm{~mm}$ and $10.1 \mathrm{sec}$ at $7.5 \mathrm{~mm}$. An empirical formula obtained (average life $\tau$ sec at $D \mathrm{~cm}$ in diameter) is
\end{abstract}

$$
\tau=3.40 \times 10^{6} e^{-17.0 \mathrm{D}} \text {. }
$$

The number of droplets produced by breaking of a drop increases with diameter of the drop. Empirical formula is obtained for the size distribution of the droplets.

No marked difference is found between the results of the experiment at a room temperature and those at $0^{\circ} \mathrm{C}$.

\section{Introduction}

Breaking of raindrops may be one of the important factors which determine the size distribution of raindrops in violent convective storm and those beneath the melting band in freezing clouds if large ice pellets and snow flakes become unstable in maintaining their shapes during melting process. The breaking of raindrops would have further importance if a chain reaction in generation of raindrops proposed by Langmuir (1948) took place actually in a convective cloud system.

Lenard (1904) and Blanchard (1950, 1951, 1957) reported the character of breaking of drops and their critical diameter of instability. Lenard's critical diameter is $8 \mathrm{~mm}$ and Blanchard's value is $8 \mathrm{~mm}$ in still air and $5 \mathrm{~mm}$ in turbulent air. Fournier d'Albe and Hidayetulla (1955) reported the size distribution of droplets produced by breaking of a falling drop which was released from a height of $20 \mathrm{~m}$ in open air. Concerning a state of free fall of drops, Magono (1954)

* Division of Physics of Atmosphere and Hydrosphere, Contribution No. 5 observed the shape of raindrop by taking photograph. Considerations and opinions have been presented by Mason (1957) on the breaking of drops and the significance of breaking in tne rain cloud.

On the other hand, in the theoretical treatment of chain reaction, a sharp critical diameter was assumed; for instance, Langmuir (1948) and Ludlam (1951) adopted $6 \mathrm{~mm}$ as its value. In these studies, raindrops were assumed to break up immediately after they attained the critical value during growth due to accretion in a cloud.

But, general consideration about the growth of capillary-gravitational waves on the water surface (described later in the present article) seems to suggest that a larger drop has a larger probability of breaking. The critical size of drop instability must not be very sharp. Instead, gradual growth of instability with increasing drop diameter may be the case.

The purpose of the present article is to obtain a quantitative relation between the probability of breaking and the drop diameter together with the size distributions of droplets produced by the breaking of a drop at a room temperature and at $0^{\circ} \mathrm{C}$. Water drops 
were suspended freely in a vertical air stream and their breakings were observed. A device of the vertical wind tunnel reported by Blanchard (loc. cit.) was adopted with slight modification with respect to the collection of droplet fragments.

A series of experiments on breaking of drops were conducted at a room temperature and other series were made at about $0^{\circ} \mathrm{C}$ in a refrigerated room. This was undertaken to see if the temperature gave rise to a difference of the drop instability due to changes in the surface tension and viscosity of water.

\section{Experimentals}

A schematic indication of an apparatus used to suspend a water drop freely in a vertical air stream is shown in Fig. 1. A large packing head of filter paper $(a, b, c)$ coated with water blue dye is mounted on a

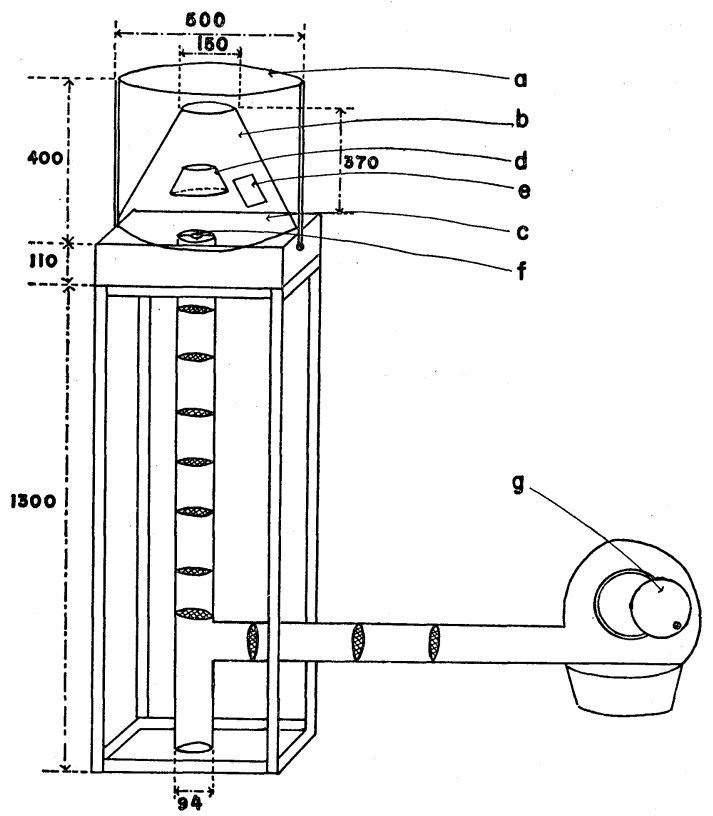

Fig. 1. Apparatus supporting a water drop (unit in $\mathrm{mm}$ ).

a. b. c. filter papers coated with water blue dye.

d. inner cap inside wall of which filter paper coated with water blue dye is adhered.

e. observation window.

f. centered screen mesh of disc shape

g. shutter of air inlet to blwer. vertical wind tunnel of Blanchard's type. Vertical wind velocities are controlled by an opening angle of a shutter $(\mathrm{g})$ at the air inlet of the blower. The wind velocities used in the experiment ranged from $8 \mathrm{~m} / \mathrm{sec}$ to $10 \mathrm{~m} / \mathrm{sec}$ for a smaller and a larger drop to be suspended freely.

As a preliminary test, the relation between the diameter of the centered mesh screen (f) and the time interval during which the upward air stream can suspend a drop was studied at a fixed height of an inner cap (d). The result is illustrated in Fig 2. In this case the diameter of $3.4 \mathrm{~cm}$ was found to be most favourable, at which condition a water drop escaped outwards from the air stream after $26 \mathrm{sec}$, on the everage, from the beginning of suspension. Next, the relation between the height of the inner cap (d) above the top of the wind tunnel and the time interval of suspending a water drop was determined at a fixed diameter of screen (f) $3.4 \mathrm{~cm}$ (Fig. 3). It was found that the height of $17.0 \mathrm{~cm}$ of the cap gave the most favourable condition where the drop could be suspended for infinite time length without escaping from the air stream. Only the

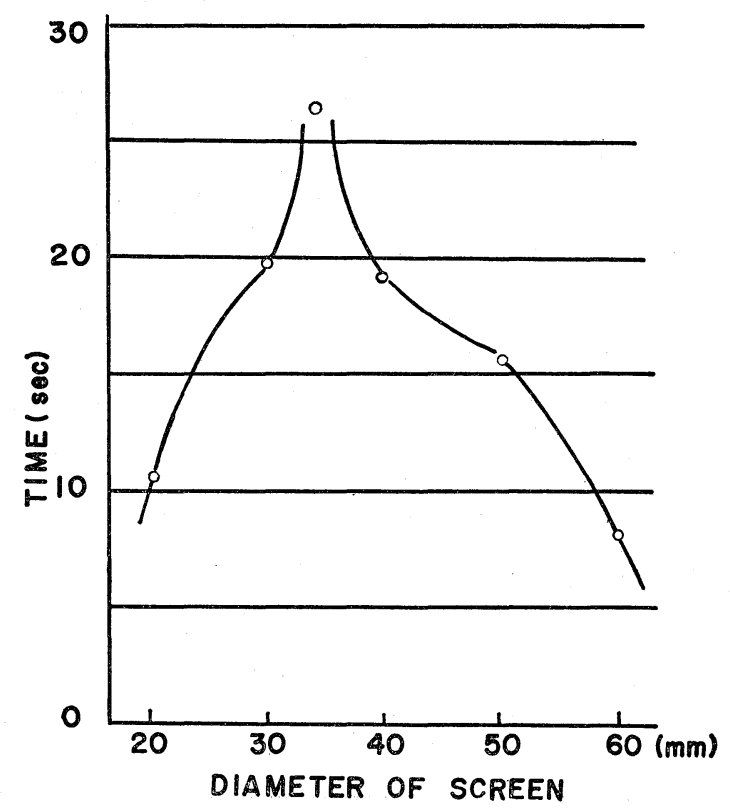

Fig. 2. Duration of suspension of drop before escaping out. Diameter of centered mesh screen is varied, keeping height of inner cap fixed at $20.5 \mathrm{~cm}$. 


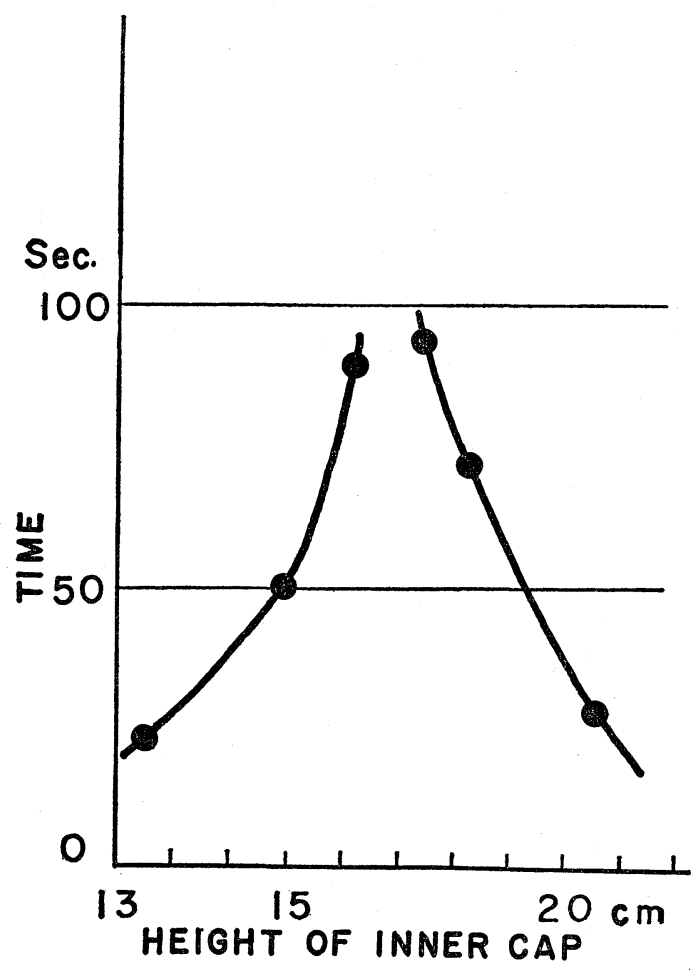

Fig. 3. Duration of suspension of drop before escaping out. Height of inner cap is varied, keeping diameter of centered mesh screen fixed at $3.4 \mathrm{~cm}$.

breaking itself forced the free suspension of the drop to come to end. At the choice of these values, that is, the diameter of the centered screen (f) $3.4 \mathrm{~cm}$ and the height of the inner cap (d) $17.0 \mathrm{~cm}$, a drop of liquid paraffin could be suspended freely in the vertical air stream continually for five hours. So this set of values has' been adopted to suspend a water drop during our experiment.

Distilled water prepared in a copper walled distillor was used in the experiment. A glass pipe with a turned edge and a springe (i) in the opposite side (Fig. 4) was used to form a water drop of a known volume. When the largest drop was required, the edge (h) was inserted into a portion of the strongest upward air stream with a slight lift

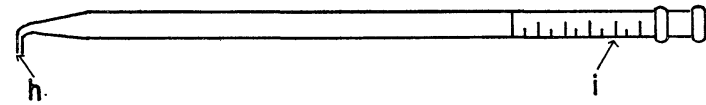

Fig. 4. Glass pipe used to form a drop of required volume. of the edge after the required volume of water was carefully pushed out, the drop was separated from the edge to begin floating. When the smaller drop was required, the edge of the glass pipe was inserted into a portion of less strong current, where the smaller drop was separated from the edge successfully by gravity on account of weaker suspending force. Thus, each $0.25 \mathrm{~mm}$ width in equivalent diameter of suspended drops could be discriminated.

Four sheets of filter papers coated with water blue dye were used to collected the droplets produced by breaking of a suspended drop. Two of them were circular disc shaped sheets. The one was mounted at the top (a). The other was set at the bottom (c) of the collecting space. The remaining two sheets were conical planes with different sizes. The one was covered on the inner surface of the inner cap (d). The other (b) was used as a lateral boundary. A small window (e) was kept open on the lateral filter paper through which the glass pipe (h-i) was inserted to form a suspended drop. Visual observation was made by use of the same window.

The time interval from the beginning of suspension to the breaking of a drop was measured by a stop-watch in a visual observation. The size distribution of the droplets produced by breaking was determined from droplet spots injected on the dyed filter paper. Water drops of $4.5,5,5.5,6,6.5,7$ and $7.5 \mathrm{~mm}$ in diameter were suspended and observed.

A series of experiments were made at a room temperature. Another series were made at about $0^{\circ} \mathrm{C}$ in a refrigerated room. Wetbulb temperature of the room was set at $0^{\circ} \mathrm{C}$ or a slightly above it.

\section{Life time of water drop before breaking}

The time interval from the beginning to breaking of a drop, or a life time of a water drop was measured for every drop suspended in the vertical air stream. Even for drops of the same diameter, individual life times were different. Breaking took place within ten seconds in some cases, while drops continued to keep their shapes beyond 250 seconds. As is well known about the disintegration of radioactive matter, an idea of 


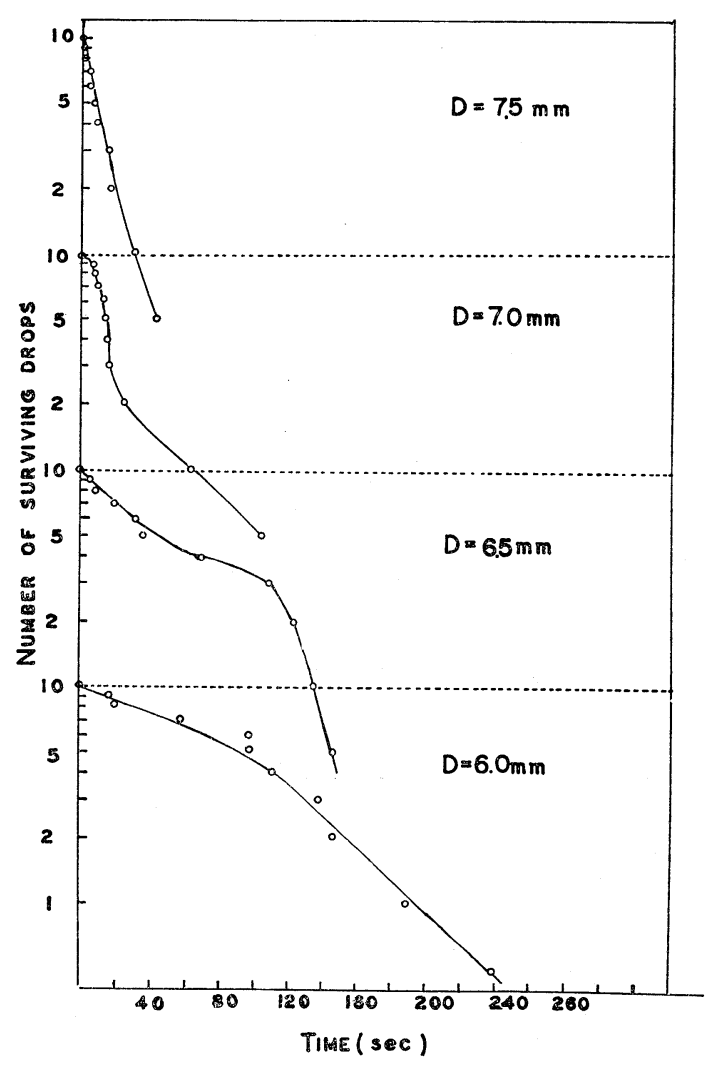

a

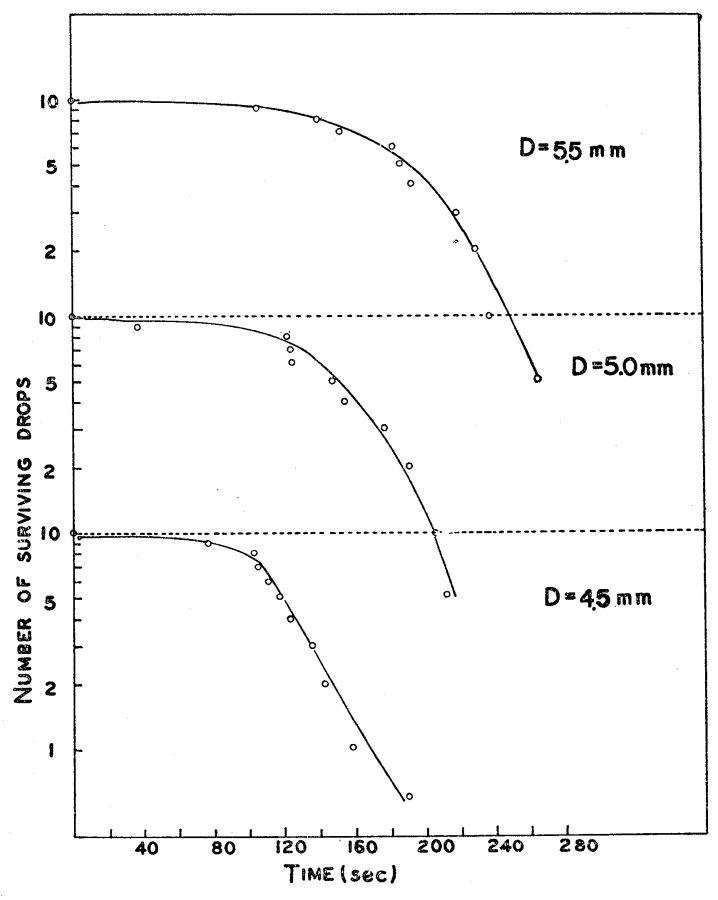

b

Fig. 5. (a), (b) Life time of drop before breaking at $19.1^{\circ} \mathrm{C}$. abscissa: time, ordinate: number of drops surviving till stated time.

random occurrence of breaking of water drops seems to be useful to understand the results of the experiment. The concepts of the half life or the average life time, and the coefficient of decay or the probability of breaking may be available.

In Fig. 5, cumulative number of water drops being suspended within a given time is indicated for each drop diameter. For instance, in Fig. 5, $D=6.0 \mathrm{~mm}, 10$ drops are suspended initially, 4 drops still survive at 110 seconds from the beginning and the final drop breakes at 238 seconds. The final instance (longest life time) corresponds to the time when the cumulative number becomes zero. On the logarithmic scale of the coordinate, the spot is plotted at 0.5 instead of 0 . A smoothed curve is drawn to show a decreasing tendency of the cumulative number with elapsed time in each semi-logarithmic diagram.
If the breaking occurred completely at random, the points should be on a straight line, of which gradient would represent the constant of decay. In the present experiment, however, the decreasing tendency does not fit a strict straight line, but shows generally increasing negative gradient with increasing time. This means that the probability of breaking grows larger with increasing time of suspension of water drops. The reason of the increase in probability of breaking with time has not yet been fully clarified, but the variation in surface tension, surface rigidity and viscosity due to increase in contamination of the drop by aerosol adhesion may give large influence on it.

The life time of drops smaller than $5.0 \mathrm{~mm}$ in diameter shows a tendency different from that of drops larger than $5.5 \mathrm{~mm}$. In the former size range smaller drops have the shorter life time. As is discussed in later 
section, this is considered to be an acceleration of free oscillation of the drop due to a resonance effect with a turbulent air motion behind the centered mesh screen. Fundamental mode or the first harmonic mode of the free oscillation of water drops smaller than $5 \mathrm{~mm}$ in diameter has frequencies more or less close to the frequency of separation of vortecies from the screen of $3.4 \mathrm{~cm}$ diameter at the wind velocity of about $8 \mathrm{~m} / \mathrm{sec}$.

Deviations of the decreasing tendency from a straight line (Fig. 5) are more significant for drops $4.5,5$ and $5.5 \mathrm{~mm}$ than for ones larger than $6 \mathrm{~mm}$ in diameter.

If we regard the time when the cumulative number of surviving drops becomes a half of the initial value as a half life of the drop, we can determine the half lives of

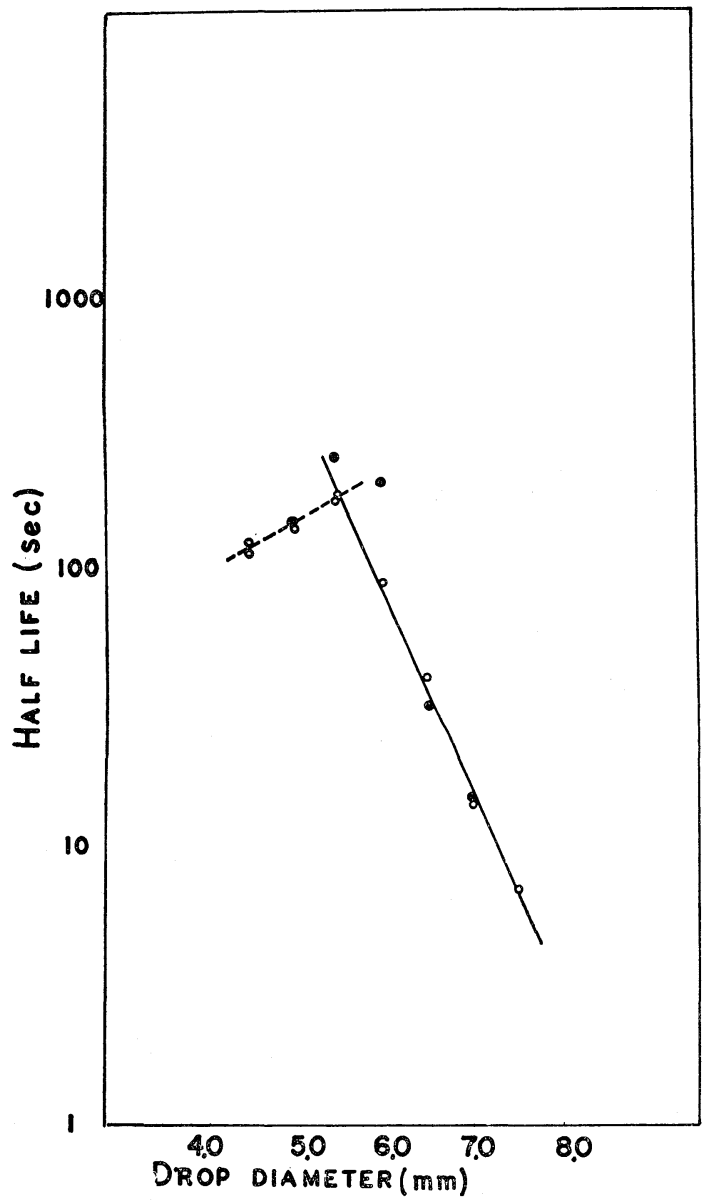

Fig. 6. Half life of drop versus drop diameter. Open circles: Those at $19.1^{\circ} \mathrm{C}$, solid circles : those at $0^{\circ} \mathrm{C}$.
Table 1. (a) Breaking of drops at $19.1^{\circ} \mathrm{C}$

\begin{tabular}{ccccc} 
Drop & Half life & Average & $\begin{array}{c}\text { Average } \\
\text { fall } \\
\text { distance } \\
\text { before } \\
\text { breaking }\end{array}$ & $\begin{array}{c}\text { Pro- } \\
\text { bability } \\
\text { of } \\
\text { breaking }\end{array}$ \\
\hline $\mathrm{mm}$ & $\mathrm{sec}$ & $\mathrm{sec}$ & $\mathrm{m}$ & $\mathrm{sec}^{-1}$ \\
7.5 & 7.0 & 10.1 & 101 & $9.90 \times 10^{-2}$ \\
7.0 & 13.5 & $19 \cdot 4$ & 194 & $5.15 \times 10^{-2}$ \\
6.5 & 44.0 & 63.4 & 609 & $1.58 \times 10^{-2}$ \\
6.0 & 92.0 & 133 & 1,220 & $7.53 \times 10^{-3}$ \\
5.5 & 190 & 273 & 2,520 & $3.66 \times 10^{-3}$ \\
5.0 & 148 & 213 & - & - \\
4.5 & 120 & 173 & - & - \\
\hline
\end{tabular}

Table 1. (b) Breaking of drops at $0^{\circ} \mathrm{C}$

\begin{tabular}{ccccc}
\hline Drop & Half life & $\begin{array}{c}\text { Average } \\
\text { life }\end{array}$ & $\begin{array}{c}\text { Average } \\
\text { fall } \\
\text { distance } \\
\text { before } \\
\text { breaking }\end{array}$ & $\begin{array}{c}\text { Pro- } \\
\text { bability } \\
\text { of } \\
\text { breaking }\end{array}$ \\
\hline $\mathrm{mm}$ & $\mathrm{sec}$ & $\mathrm{sec}$ & $\mathrm{m}$ & $\mathrm{sec}^{-1}$ \\
7.5 & - & - & - & - \\
7.0 & 15.0 & 21.6 & 216 & $4.63 \times 10^{-2}$ \\
6.5 & 32.0 & 46.1 & 442 & $2.17 \times 10^{-2}$ \\
6.0 & 235 & 338 & 3,110 & $2.96 \times 10^{-3}$ \\
5.5 & 261 & 393 & 3,600 & $2.54 \times 10^{-3}$ \\
5.0 & 153 & 220 & - & - \\
4.5 & - & - & - & - \\
\hline
\end{tabular}

drops over whole size ranges indicated in Fig. 5. It should be noted that the half life thus determined is not strict one since the decreasing tendency of the logarithm of the cumulative number with time is not strictly linear. It may be expected, however, that this half life can be used conveniently to indicate an approximate magnitude of probability of breaking as a function of drop size. Especially in a size range around $6 \sim 7$ $\mathrm{mm}$ in diameter, the half life has more strict meaning since the decreasing tendency on the diagram fits well a straight line. In Fig. 6 and Table 1, the half life is plotted against drop diameter. In both size ranges bounded by $5.5 \mathrm{~mm}$, the half lives fit a straight line respectively on the semi-logarithmic diagram. Physical meaning of these straightness has not yet been known, but equipartition of kinetic energy on some latent wave disturbances among which a paticular wave develops to break the drop might be imagined as a possible explanation.

In Table 1 , average life time where the cu- 
mulative number of suspended drops reaches $1 / \mathrm{e}$ of the initial value, average fall distance (average life time multipied by fall velocity), probability of breaking (inverse of average life) are calculated from the values of half life and indicated.

Empirical formulae of the values tabulated in Table 1 are expressed as follows, the half life $\tau_{h}$ sec of a water drop $D \mathrm{~cm}$ in diameter

$$
\tau_{h}=2.36 \times 10^{6} e^{-17.0 D} ., D \geqq 0.55 \mathrm{~cm} .
$$

The average life time $\tau$ sec is

$\tau=1.44 \tau_{h}=3.40 \times 10^{6} e^{-17.0 D}$., $D \geqq 0.55 \mathrm{~cm}$.

The probability of breaking $p \mathrm{sec}^{-1}$ is

$$
p=1 / \tau=2.94 \times 10^{-7} e^{1.70 D} ., D \geqq 0.55 \mathrm{~cm} .
$$

The temperature of the air of the experiments mentioned above was about $19.1^{\circ} \mathrm{C}$ and the relative humidity was at about $50 \%$.

The result of the experiment at about $0^{\circ} \mathrm{C}$

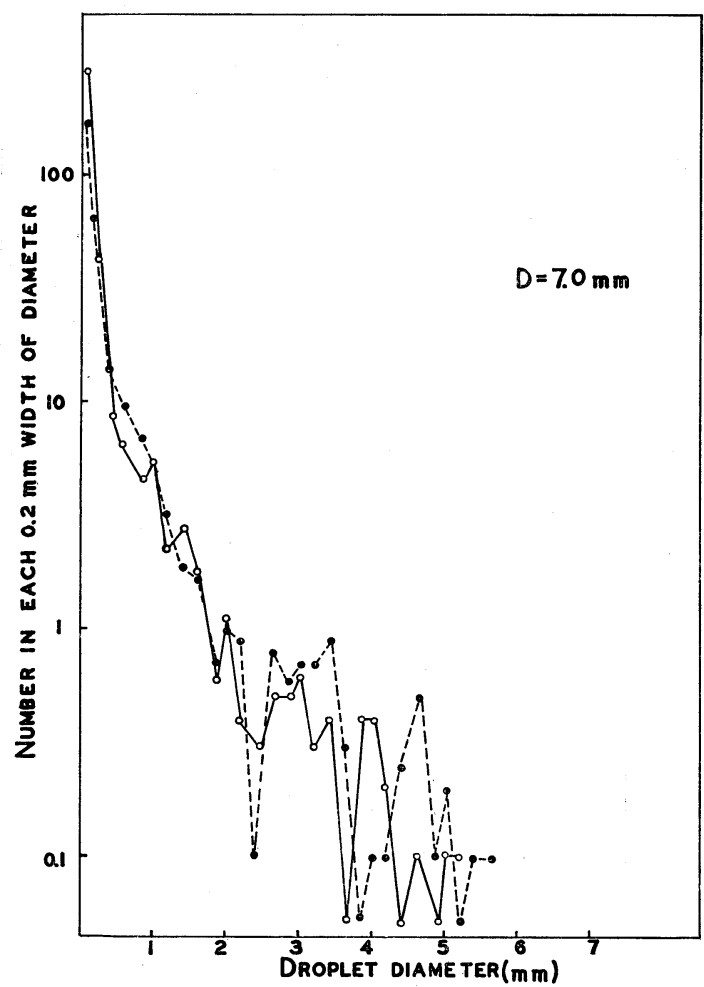

Fig. 7. (a) Number of droplets produced by breaking of a $7.0 \mathrm{~mm}$ drop. Abscissa: droplet diameter, ordinate: number at $0.2 \mathrm{~mm}$ range. Numbers at 0.1 and $0.2 \mathrm{~mm}$ were counted at $0.1 \mathrm{~mm}$ range, so two fold of countings are plotted. Solid line: 19. $1^{\circ} \mathrm{C}$. Dotted line : $0^{\circ} \mathrm{C}$ are indicated in Fig. 6 and Fig. 7. No marked difference can be seen between results at 19. $1^{\circ} \mathrm{C}$ and those at $0^{\circ} \mathrm{C}$.

\section{Size distribution of droplets produced by breaking of a drop}

The number of droplets produced by breaking of a drop was counted at each $0.2 \mathrm{~mm}$

Table 2. Cumulative number of droplets produced by breaking of a drop (Average of that at 19.1 and that at $0^{\circ} \mathrm{C}$ )

\begin{tabular}{cccccc}
\hline $\begin{array}{c}\text { Droplet } \\
\text { diameter } \\
(\mathrm{mm})\end{array}$ & \multicolumn{5}{c}{ Parent drop diameter (mm) } \\
\cline { 2 - 6 } & 5.0 & 5.5 & 6.0 & 6.5 & 7.0 \\
\hline $0.1<$ & 18.5 & 61.0 & 144 & 160 & 168 \\
$0.2<$ & 12.0 & 30.5 & 67.0 & 75.0 & 74.0 \\
$1.0<$ & 4.1 & 7.7 & 15.0 & 18.5 & 18.5 \\
$2.0<$ & 2.2 & 3.8 & 4.6 & 5.1 & 5.6 \\
$3.0<$ & 1.1 & 1.5 & 1.8 & 2.8 & 3.2 \\
$4.0<$ & 0.3 & 0.5 & 0.7 & 0.8 & 1.1 \\
$5.0<$ & 0 & 0 & 0.2 & 0.2 & 0.3 \\
$6.0<$ & 0 & 0 & 0 & 0 & 0 \\
\hline
\end{tabular}

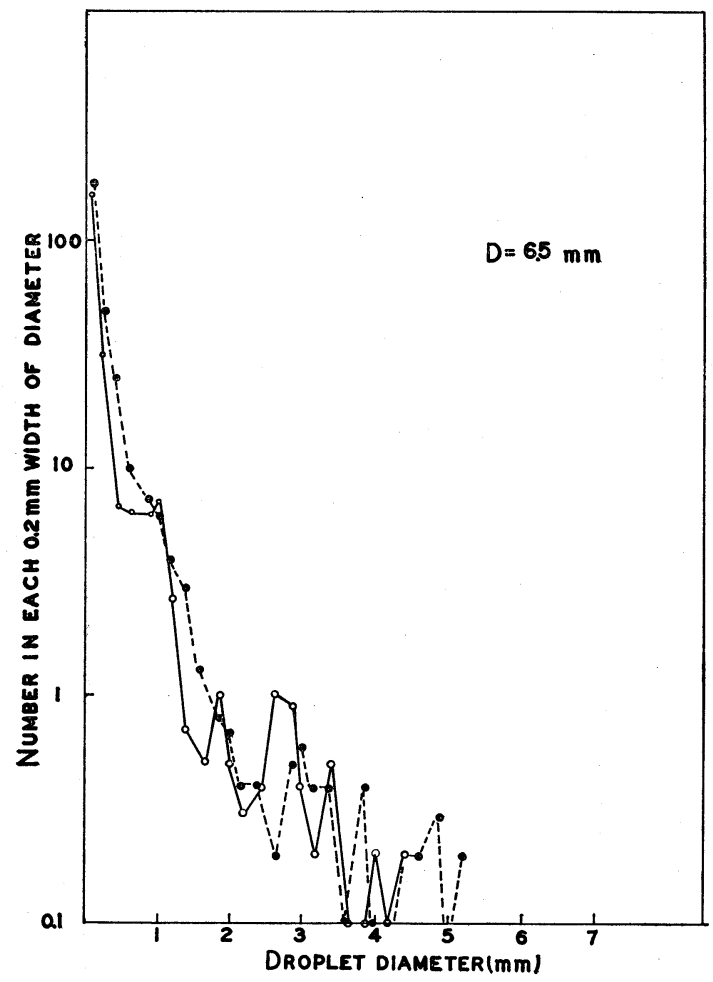

Fig. 7. (b) Number of droplets produced by breaking of a $6.5 \mathrm{~mm}$ drop. Abscissa : droplet diameter, ordinate: number at $0.2 \mathrm{~mm}$ range. Numbers at 0.1 and $0.2 \mathrm{~mm}$ were counted at $0.1 \mathrm{~mm}$ range, so two fold of countings are plotted. Solid line: $19.1^{\circ} \mathrm{C}$. Dotted line : $0^{\circ} \mathrm{C}$ 


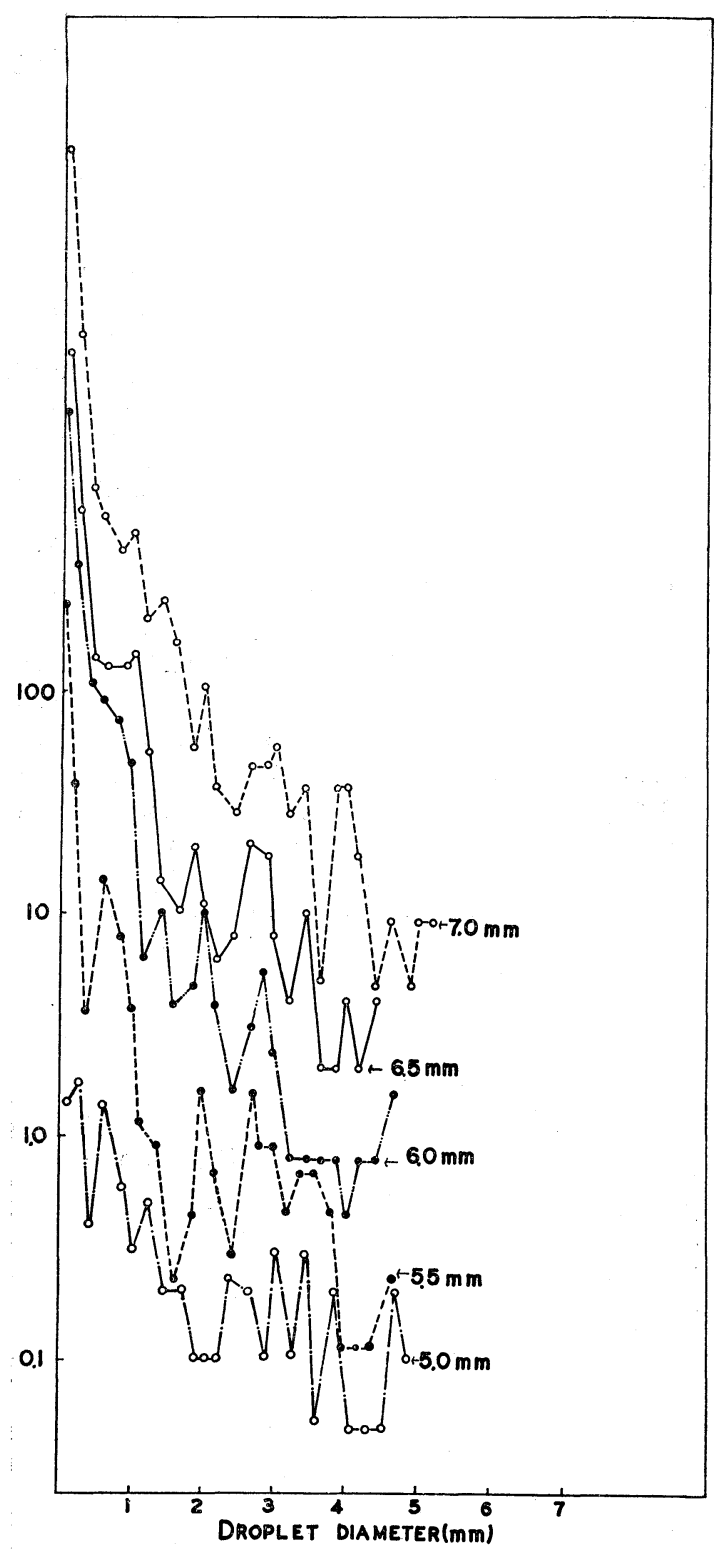

Fig. 7. (c) Number of droplets produced by breaking of a drop at $19.1^{\circ} \mathrm{C}$. Curves of different parent drop diameters are indicated with a slight vertical shift. Each arrow indicates level of 0.1 .

width in droplet diameter. Size distributions of droplets from a drop of same diameter were different case by case. In Table 2, the average size distribution of droplets from one drop are tabulated in cumulative form, which has been obtained from the superposition of the individual results of 10 to 20 drops of same size.
In Fig. 7 ( $a, b, c)$, the size distributions are presented. Each average distribution is not a monotonous function of diameter, but shows a wave like variation superposed on a decreasing trend with diameter. This wave like variation in each distribution curve resembles one another. In Fig. $7 \mathrm{c}$, all curves obtained are shown with some vertical shift to prevent the confusion. The reason that the number of droplets produced by breaking shows the wave like variation or the reason that droplets produced by breaking are apt to be concentrated in discrete size ranges is probably due to discrete wave spectrum of free oscillation of the form of the drop.

Cumulative numbers of droplets larger than indicated diameter are shown in Fig. 8. It can be seen that the cumulative number is increasing with increase in diameter of the parent drop.

A simple empirical formula which can represent a monotonous decreasing distribution

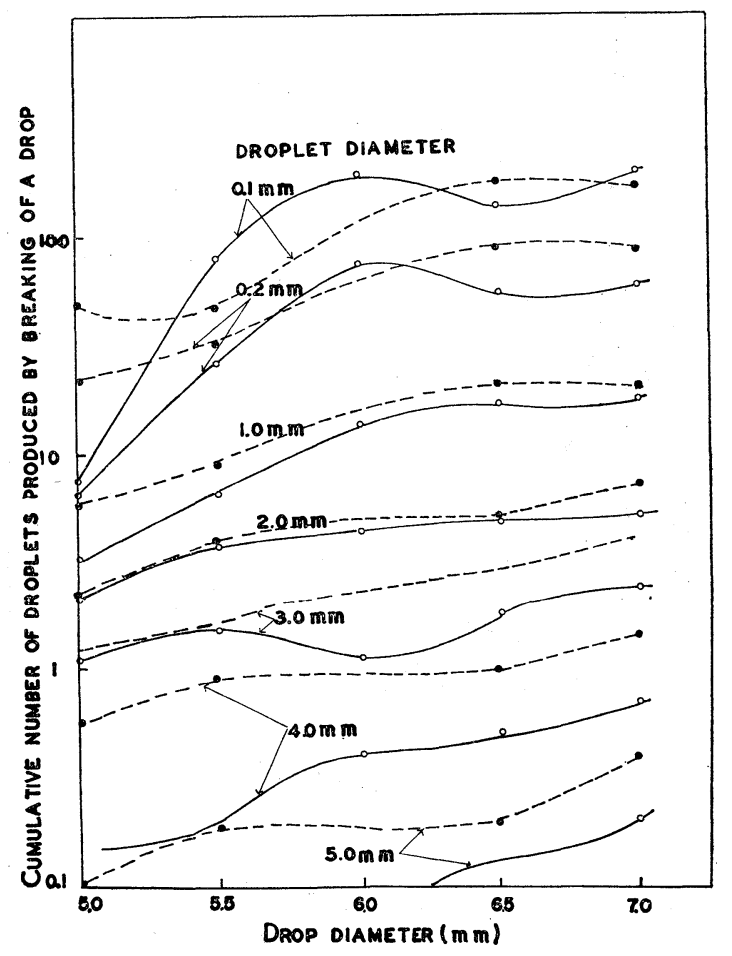

Fig. 8. Cumulative number of droplets produced by breaking of a drop. Abscissa : parent drop diameter, ordinate: number of droplets larger than indicated droplet diameter. Solid line at $19.1^{\circ} \mathrm{C}$, dotted line at $0^{\circ} \mathrm{C}$. 
of drops with neglect of the wave like variation and with neglect of the difference between curves at $19.1^{\circ} \mathrm{C}$ and those at $0^{\circ} \mathrm{C}$

$$
N(D) \delta D=6.25 \times 10^{-2} D_{0}^{3} e^{-7.8 D} \delta D
$$

where $N(D) \delta D$ is the number of droplets at the range of diameter between $D \mathrm{~cm}$ and $D+\delta D \mathrm{~cm}, D_{0}$ is the diameter of a parent drop in $\mathrm{cm}$. This formula is only a very crude one expressing the outline of the varia. tion of size distribution of droplets as a function of the diameter of a parent drop at wide temperature ranges from $0^{\circ} \mathrm{C}$ to $19.1^{\circ} \mathrm{C}$.

\section{Discussion of results}

The most fundamental question in interpreting the results of the present experiment concerns the similarity between a freely suspended drop in a vertical wind tunnel and a drop falling in the natural atmosphere. In our wind tunnel, a water drop was freely suspended with a vertical oscillatory migration around a mean position. The amplitude and the frequency of the oscillation were about $1.5 \mathrm{~cm}$ and a few cycles per seconds respectively. In the case of a drop of a liquid paraffin, however such oscillatory migration did not occur, but the drop was suspended as if it were fixed on a fibre. When a water drop was frozen during free suspension in a refrigerated room, the frozen oblate sphere continued to be freely suspended with slight oscillation like the paraffin drop. When the air stream was heated by an electric wire heater, the vertical oscillation of its position was found to take place again after melting. Therefore, the oscillation in position is considered to reflect a periodic variation of a fall velocity of the drop. Periodic deformation of the water drop due to the free oscillation developping on the surface of the drop is considered to cause a corresponding variation in the drag coefficient and hence to cause the variation of the fall velocity. In the case of a drop of liquid paraffin such periodic deformation cannot develop on account of its high viscosity and low surface tension, and accordingly the fall velocity does not vary and the position of the drop is fixed. The circumstances is considered to be similar in a case of frozen water drop. Accordingly, the fall velocity of a water drop is expected to fluctuate even in the free atmosphere due to the free oscillation of its shape. So far as the oscillatory migration of drop is concerned, the wind tunnel and the natural atmosphere may have no important difference.

Next, the interference of the turbulence in the wind tunnel to the oscillation of drop shape must be checked. It is considered that the separation of vortex in the back of the centered screen and the pulsation in the wind velocity due to a character of the wings of the blower are main sources of the turbulence. In Fig. 9, estimated frequencies of these periodic air motions are indicated together with the frequency of a free oscillatory deformation of a drop and that of an air vortex occurring in the back of the drop. Since the frequency of the free oscillation of a large drop is very low, the resonance between it and the turbulence in the wind tunnel cannot be considered to take place. But the first harmonic oscillation of drop smaller than $5 \mathrm{~mm}$ in diameter has a frequency of tens of cycles per second, therefore there is a high possibility that the resonance takes place. The life time of a drop smaller than $5.0 \mathrm{~mm}$ in diameter has been found to have

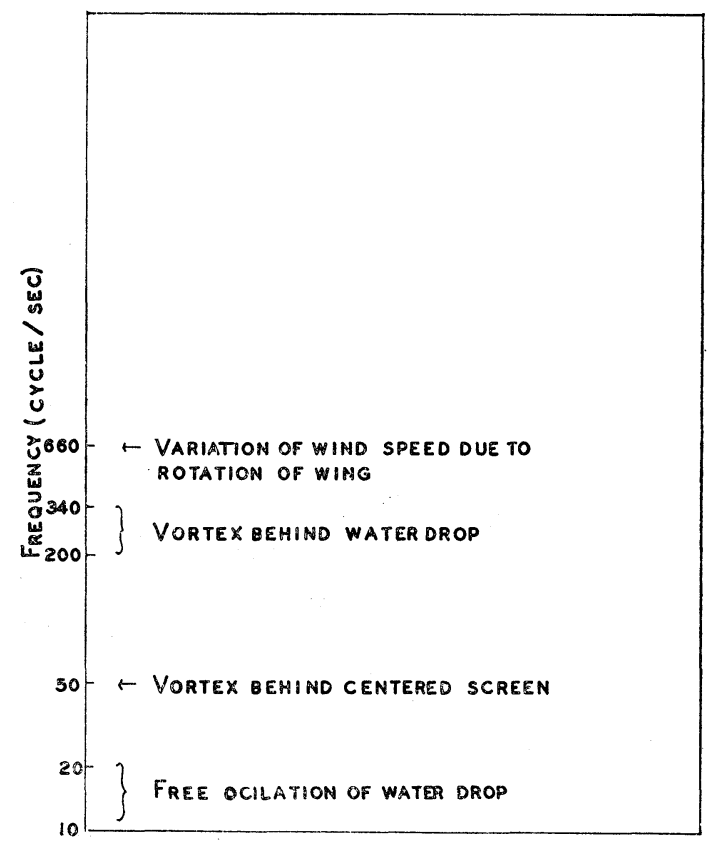

Fig. 9. Frequency of turbulence in wind tunnel. 
a different behavior from drops larger than $6 \mathrm{~mm}$ (Fig. 6). One of the possible reason of the difference is the resonance between the turbulence and the drop vibration. From this view the results of the present experiment are considered to express the breaking of a water drop falling in the natural atmosphere at least at size ranges above $5.5 \mathrm{~mm}$ in diameter. It is unsafe to conclude the result below $5.5 \mathrm{~mm}$ as a similar one to the natural breaking.

It should be noted that the value $8.5 \mathrm{~mm}$ where the drop could not be suspended without immediate breaking is a half of $1.7 \mathrm{~cm}$ which is a critical wave length between capillary waves and gravity waves on the water surface. If a theory of plane surface wave (Lamb 1932) is allowed to be applied as a first approximation to a wave on a water drop, the wave velocities on the top surface $C_{1}$ and the bottom surface $C_{2}$ (Fig. 10) are

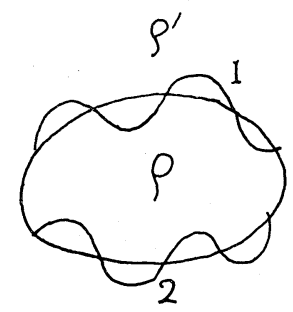

Fig. 10. (a) Waves on top and bottom surface of drop.

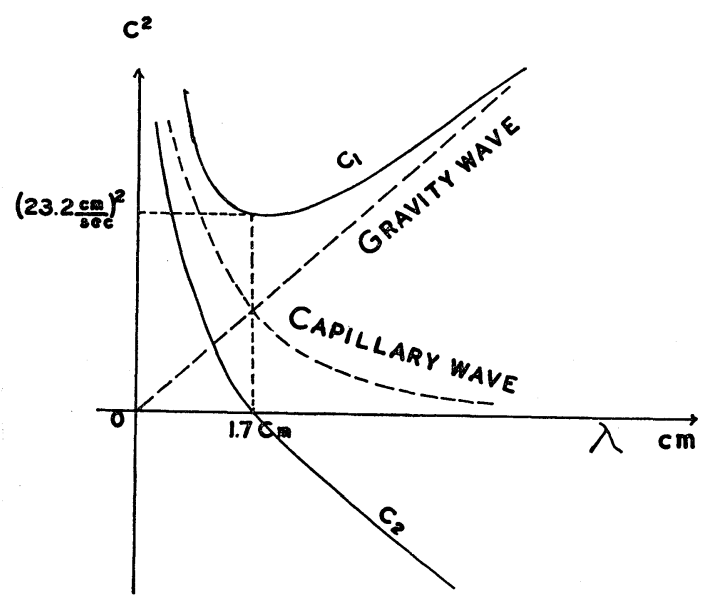

Fig. 10. (b) Square of wave velocity versus wave length.

$$
\begin{aligned}
& C_{1}{ }^{2}=\frac{\sigma}{\rho+\rho^{\prime}} \frac{2 \pi}{\lambda}+\frac{\rho-\rho^{\prime}}{\rho+\rho^{\prime}} \frac{g}{2 \pi} \lambda, \\
& C_{2}{ }^{2}=\frac{\sigma}{\rho+\rho^{\prime}} \frac{2 \pi}{\lambda}-\frac{\rho-\rho^{\prime}}{\rho+\rho^{\prime}} \frac{g}{2 \pi} \lambda,
\end{aligned}
$$

where $\rho_{1}$ and $\rho_{2}$ are the density of water and air respectively and $\sigma$ is the surface tension. The first term in the right hand side of (5) and (6) presents a capillary wave and the second term presents a gravity wave. At the wave length

$$
\lambda^{*}=2 \pi \sqrt{\frac{\sigma}{g\left(\rho-\rho^{\prime}\right)}}=1.7 \mathrm{~cm},
$$

$C_{1}$ takes a minimum value. Since the second term in the right hand side of (6) is negative, $C_{2}$ becomes imaginary for $\lambda>\lambda^{*}$. This will correspond to growing waves, or instability. The fundamental mode of free oscillation of a freely suspended drop must be a standing wave of wave length $\lambda / 2$. Thus, drop larger than $\lambda^{*} / 2$ in diameter cannot be stable. Actual breaking of a drop is a phenomenon of finite amplitude and furthermore, theory of plane wave cannot be applied to a drop strictly. This calculation must therefore be regarded as a crude quantitative basis for the estimate of instability of a drop.

Counting of droplets produced by breaking of a drop was made by means of dyed filter paper. So, droplets smaller than $100 \mu$ in diameter could not be counted completely. Photographical measurement of the number of smallest droplets will be made in the near future.

Instead of distilled water drops, in some trials drops were formed by use of the natural rainwater. Usually, the average life of them was found to be longer than distilled water drop. The examples are illustrated in Fig. $11(a, b)$. The used natural rain water was collected separately according to their drop sizes by means of a horizontal wind tunnel of the type which was deviced by Bowen and Davidson (1951) and Turner (1955). The $\mathrm{pH}$ values, $\mathrm{Cl}^{-}$and $\mathrm{Na}^{+}$concentration are indicated together with the life time of suspended drops according to their original diameter which the rainwater had took as a raindrop at the time of fall. The longer life time of a drop of rainwater may be due to favourable values of surface ten- 


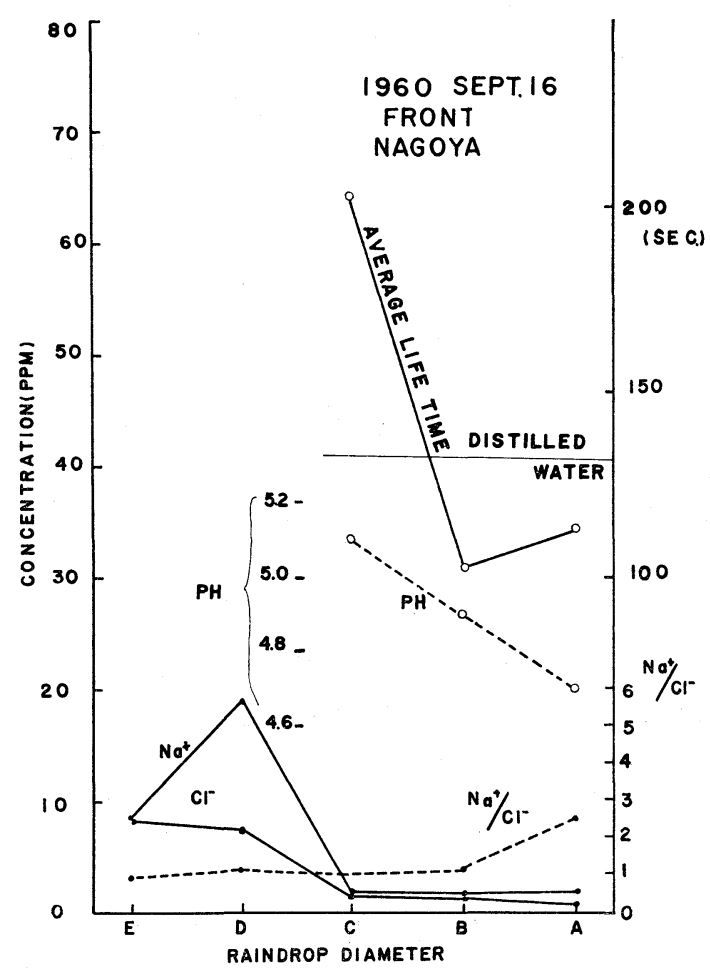

Fig. 11. (a) Average life time before breaking of $6 \mathrm{~mm}$ drops of rainwater. Rainwater of frontal rain was collected in raindrop spectrograph at NAGOYA on 16 Sept. 1963. $\mathrm{pH}, \mathrm{Cl}^{-}, \mathrm{Na}^{+}$and $\mathrm{Na} / \mathrm{Cl}$ are indicated. $\mathrm{A}, \mathrm{B}, \mathrm{C}, \mathrm{D}$, and $\mathrm{E}$ indicate original raindrop diameters at the time of rainfall. $\mathrm{A} \geqq 1.8, \mathrm{~B}=0.7, \mathrm{C}=0.4, \mathrm{D}=0.2$ and $\mathrm{E} \leqq 0.1$ $\mathrm{mm}$.

sion, surface rigidity and viscosity for suppressing the instability of the form with some amount of contamination.

\section{Acknowledgement}

The authors express their thanks to Dr. T. Takahashi and to Mr. T. Tanaka of the laboratory for their discussion and assistance during the present work. The authors are greatly indebted to Dr. D. C. Blanchard for his valuable suggestion about the device of free suspension of a water drop.

\section{References}

Blanchard, D. C. 1950: The behavior of water drops at terminal velocity in air. Trans. Amer. geophys. Union, 31, 836-842.

—— 1951: A verification of the Bally-Dorsey

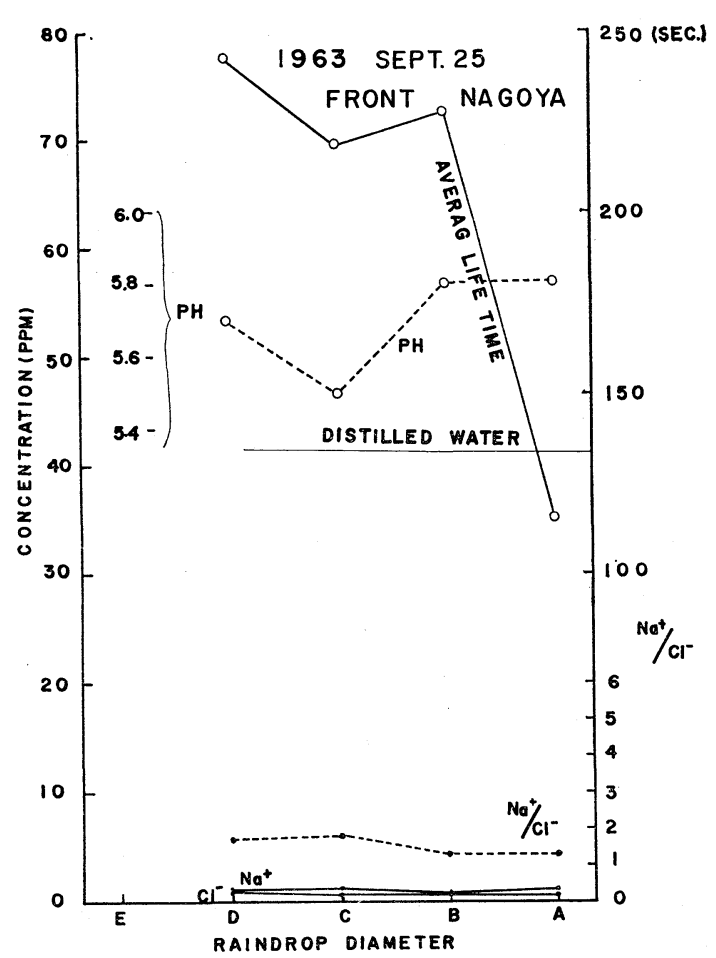

Fig. 11. (b) Average life time before breaking of $6 \mathrm{~mm}$ drops of rainwater. Rainwater of frontal rain was collected in raindrop spectrograph at NAGOYA on 25 Sept. 1963. $\mathrm{pH}, \mathrm{Cl}^{-}, \mathrm{Na}^{+}$and $\mathrm{Na} / \mathrm{Cl}$ are indicated. $\mathrm{A}, \mathrm{B}, \mathrm{C}, \mathrm{D}$, and $\mathrm{E}$ indicated original raindrop diameters at the time of rainfall. $\mathrm{A} \geqq 1.8, \mathrm{~B}=0.7, \mathrm{C}=0.4, \mathrm{D}=0.2$ and $\mathrm{E} \leqq 0.1$ $\mathrm{mm}$.

theory of spicule formation on sleet pellets. J. Meteor., 8, 268-269.

, 1957: The supercooling, freezing and melting of giant waterdrops at terminal velocity in air. Artificial Stimulation of Rain. Pergamon Press, New York, 233-249.

Bowen, E. G. and K. A. Davidson, 1951: A raindrop spectrograph. Quart. J. Roy. meteor. Soc. 77, 445-449.

Fournier d'Albe, E. M. and M. S. Hidayetulla 1955: The break-up of large water drops falling at terminal velocity in free air. Quart. J. Roy. meteor. Soc., 81, 610-613.

Lamb, H., 1932: Hydrodynamics. Cambridge Univ. Press., 6th edit. pp.458-461,

Langmuir, I., 1948: The production of rain by a chain reaction in cumulus clouds at temperatures adove freezing. J. Meteor., 5, 175-192.

Lenard, P., 1904: Über Regen. Meteor. Zeit., 21, 248-262. 
Ludlam, F. H. 1951: The production of showers by the coalescence of cloud droplets. Quart. J. Roy. meteor. Soc., 77, 402-417.

Magono, C., 1954: On the shape of water drops falling in stagnant air. J. Meteor., 11, 77-79.
Mason, B. J., 1957: The Physics of Clouds. Oxfoad at the Clarendon Press.; 437-439.

Turner, J. S. 1955: The salinity of rainfall as a function of drop size. Quart. J. Roy. meteor. Soc., 81, 418-429.

\title{
浮ゆうする水滴の分裂確率と分裂後の粒度分布
}

\author{
駒 林 誠, 権田武彦, 礒野 謙治 \\ 名古屋大学理学部水質科学研究施設
}

重直気流の中に自由に浮ゆうする水滴についてその分裂確率を種々の水滴直径飞ついて実験的に定めた。その結果 によれば分裂確率は水滴の直径の増加と共に指数函数的に増大し，分裂までの平均寿命時間は直径 $5.5 \mathrm{~mm}$ で 273 秒，6.5 mm で 63.4 秒， $7.5 \mathrm{~mm}$ で 10.1 秒である。直径 $D \mathrm{~cm}$ の水滴の平均寿命時間 $\tau$ 秒は次の実験式で表わ すことができる。

$$
\tau=3.40 \times 10^{6} e^{-17.0 D}
$$

水滴の分裂によって生ずる小水滴の個数ははじめの永滴の直径が大きいほど多い。小水滴の粒度分布を奏駼的に定 め，その奉験式を与えた。

室温と $0^{\circ} \mathrm{C}$ 附近の温度で実験を行なったが両者の間には著しい差は認められなかった。 